\title{
Systemic Challenges, Stigma, and Solutions: Experiences of Black Men Who Have Sex with Men in Tennessee
}

\author{
Sandra L. Barnes ${ }^{1, *}$ \\ ${ }^{1}$ Vanderbilt University, 230 Appleton Place, Nashville, TN, USA \\ *Corresponding author: Vanderbilt University, Peabody \#90, 230 Appleton Place, Nashville, \\ TN, USA. Tel: 1-615-322-8714. E-mail: sandra.1.barnes@ vanderbilt.edu
}

Received: July 8, 2019 Accepted: October 9, 2019 Published: November 4, 2019

doi:10.5296/jsr.v11i1.15756 URL: https://doi.org/10.5296/jsr.v11i1.15756

\begin{abstract}
Much of the research on black Men Who Have Sex with Men (BMSM) focuses on health disparities in HIV occurrence and retroantiviral medication adherence. Although important, this emphasis is often at the expense of other areas of their lives. This study endeavors to better understand systemic challenges, including stigma, and responses for a group of BMSM who reside in a moderately-sized metropolitan city in Tennessee. Focus group results, black feminism, and content analysis are used to examine their experiences and coping mechanisms. Respondents describe circumstances they associate with inequities linked to race, class, sexual orientation, gender and their intersection. Other themes emerged around: self-help; innovative family forms; and, the need for collective mobilization. Equally important was the desire for group and individual identities that do not reduce BMSM to stereotypes linked to HIV/AIDS. In addition to illustrating the usefulness of black feminism to illumine the lives of historically marginalized groups beyond women, results suggest the need for solutions that attend to the unique challenges and capacities of BMSM.
\end{abstract}

Keywords: Black men who have sex with men, stigma, HIV, black feminism 


\section{Introduction}

Much of the research on black Men Who Have Sex with Men (BMSM) focuses on HIV/AIDS or the impact this disease has on their lives such as HIV occurrence and retroantiviral medication adherence (Bennett, 2013; Centers for Disease Control and Prevention [CDC], 2016), 2016a; Hawkins, 2011; Millet et al., 2006; Millet et al., 2007). This emphasis is important given the disproportionate percentage of BMSM affected by the disease. But what other challenges are important to BMSM that are not HIV/AIDS-related? How are such situations influenced by factors such as race, class, age, gender, and sexual orientation? And can black feminism as a paradigm be applied to understand their experiences? I consider these questions for a cadre of eight BMSM ages 18-24 years old who reside in a metropolitan city in Tennessee. This study relies on black feminism as a theoretical framework and content analysis of focus group data to assess systemic issues, stigma, and possible resolutions. Rather than generalizability in the traditionally academic sense, the goal here is specificity for a small group of members of this historically marginalized population. Yet certain broader implications may be possible.

The current endeavor has both scholarly and practical implications. Exploring the emotions and experiences of BMSM could be beneficial for improving their life chances and quality of life by better understanding some of their; challenges, needs, capacities, histories, decisions, expectations, and aspirations. Although certain studies illustrate the adaptive, resilient nature of some BMSM (Balaji et al., 2012; Barnes, 2017; Battle et al., 2002), it will be valuable to consider more recent data on the subject. Moreover, beyond descriptions, respondents provide prescriptives both they and their allies can implement to enhance the lives of BMSM. Lastly, black feminism as a transformative model has been used to assess the lives of black women (Collins, 1990, 2004, 2009; Crenshaw, 1994, 2017; Harris-Perry, 2004, 2013; Hooks, 1999, 2015). It will be important to consider whether and how this theory can be used to examine the experiences of another historically disenfranchised group.

\section{Applying Black Feminism to Another Historically Marginalized Group}

Black feminism has been employed historically to acknowledge and document the experiences of black women as well as to consider how marginalized groups resist oppressive conditions and engage in social activism. Although this theory tends to be used to examine race, class, and gender dynamics for economically challenged black women, its' robustness makes it viable to consider other vulnerable populations such as BMSM. A black feminist lens also enables researchers to consider groups that have been understudied or researched in culturally insensitive ways. Moreover, this paradigm focuses on ways in which groups that have been economically, politically, and socially disenfranchised: are agentic in often unexpected ways; understand their own realities; and, strive to empower themselves individually and collectively (Choo \& Ferree, 2010; Collins, 1990; Harris-Perry, 2004, 2013; Hooks, 1999, 2015). It is also informative when assessing correlates between racism, anti-racism, patriarchy, violence against women of color, and political activism (Crenshaw, 1994). 
Subjugated knowledges, self-reflection, and intersectionality are important concepts associated with this theory. Collins (1990: 5-6) suggests that there is a "dialectic of oppression and activism, the tension between the suppression of Black women's ideas and our intellectual activism in the face of that suppression" that can be applied to BMSM who, despite being male, have a history of navigating racism, homophobia, and for many, classism. According to this theory, such groups develop subjugated knowledges or personal wisdom for resistance as they live as "outsiders" in the larger society; they also create counter-narratives that enable them to cultivate positive images and self-definitions despite unfavorable depictions about them. These survival strategies mean marginalized groups are able to identify stereotypes and other pejorative attitudes and actions conveyed by majority groups, reject them, and purposely create their own more empowering alternatives.

According to Collins (1990), "people who are oppressed usually know it. For African-American women, the knowledge gained at the intersection of race, class, and gender oppression provides the stimulus for crafting and passing on the subjugated knowledge of a Black women's culture of resistance" (p. 11). However, this transformative process is undermined by factors such as power, violence, and other systematic forces designed to subvert these efforts, blame minorities for their plight, or disavow or downplay their negative experiences. Furthermore, the matrix of domination reflects the complicated, pervasive, interdependent, and relational process by which systemic oppression occurs based on individuals' multiple minority identities (Choo \& Ferree, 2010; Collins, 1990; Crenshaw, 1994, 2017). This study considers whether and how a group of BMSM experience similar forms of oppression and resistance as well as some of the more salient challenges they face.

According to black feminism, controlling images are used by majority members to make the oppression and discrimination of minority groups palatable and acceptable (Collins, 1990). These same negative depictions are perpetuated by forces that are economic, political, social, and cultural in nature; thus resistance must address these same fronts. One can argue to, like black women, for many BMSM "the internal, psychological, emotional, and personal experiences of black women are inherently political... [they] have always had to wrestle with derogatory assumptions about their character and identity" (Harris-Perry, 2013:5). Just as controlling images such as jezebel, mammy, and matriarch rationalize the exploitation of black women, defamatory descriptives such as fag, homo, and he-she, serve to vilify MSM. BMSM often contend with these same derogatory terms and race-related negative concepts that further illustrate intersectionality and the matrix of domination;

Intersectionality is a lens through which you can see where power comes and collides, where it interlocks and intersects. It's not simply that there's a race problem here, a gender problem here, and a class or LBGTQ problem there. Many times that framework erases what happens to people who are subject to all of these things. (Crenshaw, 2017: n. p.)

Like many black women, BMSM may rely on self-definitions as a form of resistance and empowerment. For black women, these positive affirmations are often supported and reinforced by existing institutions, safe spaces, and experiences in the black community such 
as the black church, the black jazz tradition, and black women's groups. Such spaces and experiences are outside the purview and power of majority members and focused solely on marginalized groups. This study endeavors to identify possible ways BMSM develop self-definition and subjugated knowledges as well as places and processes that foster these efforts (Collins, 1990; West, 1993).

Scholars such as Collins (2004) have presented concerns and remedies for social problems that disproportionately impact groups such as BMSM. For example, she contends that effectual redress of HIV/AIDS must involve making individuals who feel the least directly affected become empathetic and act on behalf of those most likely to be affected; "because HIV/AIDS... does not affect just Black people, solutions require coalitions with other groups who share a similar agenda... a broad-based coalition politics. But one might ask, given the deeply entrenched nature of racism in the United States... what ideologies would sustain such a coalition?" (Collins, 2004: 298). While acknowledging the disparate overall experiences of black women and BMSM, this thesis can also be applied to the experiences of the latter group. I contend that black feminism is applicable here because it: can be used to identify oppression and resistance, broadly defined; focuses on minority groups using their own voices; acknowledges that people on the margins have unique wisdom and abilities; and, intentionally examines links between individual experiences and structural challenges.

Key elements of this multi-disciplinary model that may be germane include how BMSM: 1) identify and understand the personal and collective challenges they face; 2) articulate their experiences; 3) provide examples of controlling images, subjugated knowledges, self-definition, and intersectionality; 4) engage in everyday forms of resistance; 5) foster collective activism for systemic change; 6) may or may not choose to engage in processes reflective of black feminist thought; 7) may be unable to identify, understand, or combat the sources of their oppression; and, 8) strive to create safe spaces. The objective is to assess Black feminism's usefulness to illumine stigma, structural forces, and possible solutions among the sample BMSM who, despite membership in a socially entitled gender group, share certain more marginalized social identities with black women.

\section{Literature Review}

\subsection{BMSM and HIV/AIDS}

HIV/AIDS continues to affect an increasing number of MSM, in general, and BMSM, in particular (Barnes, 2013; Hall, 2008; Mckellar, Valloeroy, \& Secura, 2005; Millet et al., 2006). For example, in 2013, gay, bisexual, and other MSM comprised about 2\% of the United States (U.S.) population, but 55\% of people living with HIV (CDC, 2016). Yet from 2010 2014, the increase in HIV diagnoses among all MSM was less than 1\%. Rates of occurrence vary based on race and ethnicity. For example, during this same period, diagnoses increased $22 \%$ among all BMSM and 87\% among young BMSM. Young BMSM between $13-24$ years old are also at an even higher risk of HIV infection than their older counterparts (CDC, 2015, 2016). In 2014, an estimated 39\% or 4,321 BMSM diagnosed with HIV were 13-24 years old; 
about 36\% (3,995 persons) were ages 25-34 years old. However, since 2010, the increase in diagnoses among BMSM has leveled off. For example, diagnoses during 2010 - 2014 among BMSM ages 13 to 24 years old, declined 2\% (CDC, 2016, 2016a). However, geographic disparities in HIV/AIDS cases are evident, particularly among BMSM in the South (CDC, 2016a). Tennessee ranks $10^{\text {th }}$ in the country in the rate of new HIV diagnoses (cases per 100,000 population) and $12^{\text {th }}$ in the rate of new AIDS cases (Tennessee Dept. of Health, 2013, 2013a; Turner, 2012).

Young BMSM are more likely than other demographic groups to acquire HIV, despite studies showing their lower levels of sexually risky behavior as compared to other MSM (Hawkins, 2011; Millet et al., 2006; Turner, 2012). Differences in HIV infection rates are partly explained by BMSM's social and sexual networks where these intersecting groups increase exposure (Millet et al., 2006; Millet et al., 2007). Yet the above statistics only provide one dimension of the multi-faceted lives of BMSM. They are presented here as a broad context to inform some of the situations BMSM in this study describe. The current analysis is not designed to ignore the deleterious effects of HIV/AIDS in this populace, but rather to focus on other dynamics BMSM experience that are important to them and affect both their life chances and quality of life.

\subsection{Experiences and Challenges among BMSM: Beyond HIV/AIDS}

Studies suggest that BMSM encounter unique dynamics based on the intersection of race, class, gender, and sexual orientation. The current analysis is informed by existing literature on the experiences of BMSM, particularly challenges and stigma. Despite protective legislation, more inclusive media, and greater general acceptance, negative attitudes towards the LGBTQIA community persists, in general, and particularly for persons of color (Battle et al., 2002; Lemelle \& Battle, 2004; Nelson \& Krieger, 1997).

Berrill (1990) suggests that over 90\% of persons who are LGBT have experienced discrimination; nearly $20 \%$ of all hate crimes in 2000 were linked to sexual orientation (Jenkins et al., 2007). Such victimization has particularly affected gay youth in the form of disproportionate levels of substance abuse and suicidal ideation than their peers (Baumrind, 1995; Micah, 2002). Stigma can be compounded for BMSM, as they may encounter discrimination based on both their racial and sexual identities (Means \& Jaeger, 2015). Stigma and discrimination have been shown to negatively affect BMSM emotionally and physically (Arnold et al., 2014; Peterson \& Jones, 2009). Some studies suggest that young BMSM experience higher rates of mental illness than their counterparts in the same age groups (Blashill et al., 2011; Graham et al., 2009; Reisner et al., 2009). This vulnerability is largely a result of stressors associated with their multiple minority identities such as age, race, and sexual orientation that are known to result in inequality, discrimination, stigma, physical attacks, and homelessness from parental abandonment (Blashill et al., 2011; Choi et al., 2011; Graham et al., 2009; Jones et al., 2010).

Balaji et al.'s (2012) analysis of BMSM between that ages of 16 and 25 years old uncovered stigma within family, religious, and community contexts attributed to intolerant religious teachings, negative stereotypes about gay men, and negative perceptions about people with 
HIV. Respondents navigated challenges by "adjusting to the environment," altering or concealing their behavior to lessen exposure to discrimination or finding solace in the gay community (p. 735). Yet stigma affected their self-image and often fostered self-hate. Peterson and Jones (2009) chronicled similar negative experiences of stigma and racism for BMSM within families, religious groups, and the broader society. Arnold, Rebchook, and Kegeles (2014) also examined how racism, homophobia, and HIV-related stigma affect the experiences of BMSM ages 19 to 31 years old, as well as how coping strategies affect HIV occurrences. Negative experiences in both the larger society and black communities often resulted in: social and physical rejection; increased sexually risky behavior as BMSM sought support and intimacy from sexual partners via unprotected sex; and, decreased tendencies to seek HIV testing, disclose status, and/or seek treatment.

Perceived discrimination has been related to: disparate antiretroviral adherence rates; maladaptive coping mechanisms and health behaviors; and, cultural mistrust towards health institutions. And because one's race is more visible than HIV-serostatus or sexual orientation, BMSM are more likely to be targeted because of their race, which often results in increased stress (Bogart et al., 2010). In the absence of appropriate social support, incidents associated with stigma, homophobia, stereotypes, and racism may ultimately lead to physiological distress. The above types of challenges may cause BMSM to seek out both peers with similar stressors and supportive allies. Such networks can be essential for risk prevention efforts (Weir, Pailman, \& Mahlalela, 2003).

Whether one considers: family dynamics, relationships, and networks (Balaji et al., 2012; Oster et al., 2013); stereotypes, legal concerns, housing discrimination, and social policies (Battle \& Barnes, 2010); religiosity and church connections (Barnes, 2009; Means and Jaeger, 2015); managing racism and homophobia (Choi et al., 2011); mental health and stressors (Graham et al., 2009; Jones et al., 2010); stigma and myths about privilege, economic stability, and conspicuous consumption (Badgett, 2001); and, studies on how groups such as BMSM navigate these and other dynamics (Battle et al., 2002), it continues to be important to examine both chronic challenges for BMSM and more contemporary issues they face. Many of the above issues such as: locating low-cost housing, education, and healthcare; securing gainful employment; finding social support; and, navigating other societal quagmires, are not only experienced by BMSM. Yet this study is important given the tendency for such challenges to be exacerbated for many BMSM due to their multiple marginalized social identities. Will BMSM here note similar challenges as provided in the aforementioned literature review? What are their experiences, responses, and suggested remedies? This investigation considers these dynamics based on the voices of BMSM.

\section{Data Collection and Analysis: Illuming the Voices of BMSM}

\subsection{Data Collection}

This analysis is based on a focus group conducted during the spring of 2016 in a community-based resource center located in a metropolitan city in Tennessee. To ensure 
confidentiality, the 90-minute discussion occurred in a private room; pseudonyms are used here. Based on the pre-determined selection criteria of race (black or African American), age (18-30 years old), and self-identified sexual identity (MSM), eight men between the ages 18 and 28 years old who self-identified as BMSM participated. Their average age was 24 years old. Six of the eight participants or $75 \%$ were attending college to pursue Bachelors $(n=5)$ or Masters $(n=1)$ degrees. Seven of the eight participants $(88 \%)$ relocated to the city from another area in the U.S. (i.e., Memphis, Tennessee; Atlanta, Georgia; Dover, Delaware; or Tacoma, Washington) or country (i.e., People's Republic of Congo). Their average time in residence in the city was 3 years (refer to Table 1). Individuals were recruited using snowball sampling via fliers, word of mouth, and community partners of the researcher. Interested candidates were screened for eligibility. Participation incentives included one meal and a \$20 gift card.

The focus group was facilitated by a community member matched by race/ethnicity and trained to facilitate such groups. The gathering was designed to provide an informal, casual atmosphere to encourage open conversation. Survey questions and probes (provided upon request) were semi-structured to allow for increased responses. In addition to demographic questions, it included queries about: racial and sexual orientation; concerns and needs; and, everyday aspects of their lives. Responses were audio-recorded and transcribed by a trained transcriber and reviewed and approved by this author. The small sample precludes generalizability to the larger BMSM population. However, generalizability is not the objective here, but rather to illumine perspectives and gather thick descriptions among a group of BMSM about their lives, trials, and triumphs as well as provide possible remedies that they, their allies, and community partners could implement to potentially enhance both the life chances and quality of life of BMSM.

\subsection{Analytical Approach}

Content analysis was used to identify emergent themes and patterns in responses (Hsieh \& Shannon, 2005; Krippendorf, 1980; Neuendorf, 2002). During this qualitative process, data were categorized to uncover and identify cogent trends (Stewart \& Shamdasani, 1998). Respondents' views were systematically examined using two primary processes: open-coding, in which broad concepts during the group dialogue were labeled and categorized, and axial coding, in which connections between these concepts and possible themes were analyzed (Strauss \& Corbin, 1990). Several steps were taken during the analysis process. First, line-by-line coding was initially used to identify common verbiage among respondents. This process allowed me to identify and highlight frequently used words and phrases across each respondent. In addition, I noted non-verbal cues such as inflexions and pauses that informed respondents' meanings and emotions. I continued this process throughout the data as a straightforward first stage of capturing the most general concepts and patterns used among the sample BMSM. These emergent words and phrases were then re-examined to develop broad emergent themes.

Next, the data were examined in light of key concepts and themes from black feminism such as intersectionality, subjugated knowledges, oppression/resistance, and self-definition to 
determine whether these concepts or variations of them were evident during the discourse between respondents. This step also included assessing meaning to respondents' comments as well as whether and how they applied to the theory's key concepts. In addition to illustrating application of this theory, such results would support the viability of black feminism as a lens to better understand the lives of BMSM as well as possibly new aspects of the theory germane for them. Although the initial phase of the analysis required me to remain open to possible emergent phrases and themes, the phase during which the data were compared to common black feminist concepts meant comparing respondents' statements to a certain degree of predetermined concepts and themes from that theory. Although validity and reliability are not typical criteria for qualitative analysis, successive, multiple mining of the data provided confidence in the regularly occurring concepts and three broad themes that ultimately emerged. Emergent themes, corresponding analysis, and respondent quotes are provided below.

Table 1. Thumbnail Descriptions of Focus Group Participants

\begin{tabular}{|c|c|}
\hline Name & Thumbnail Profile \\
\hline Dominique & $\begin{array}{l}\text { - } 23 \text { years old from Memphis, TN } \\
\text { - Has lived in the city } 3 \text { years } \\
\text { - Undergraduate student (English and Philosophy major) }\end{array}$ \\
\hline Peter & $\begin{array}{l}\text { - } 25 \text { years old from Tacoma, WA } \\
\text { - Graduated from a locale college (completing M.A.) } \\
\text { - Has lived in the city } 6 \text { year }\end{array}$ \\
\hline Kenneth & $\begin{array}{l}\text { - } 23 \text { years old who currently works full-time } \\
\text { - } \quad \text { Starting school for nursing }\end{array}$ \\
\hline Samuel & $\begin{array}{l}\text { - } 25 \text { years old from the People's Republic of Congo } \\
\text { - Has lived in the city } 7 \text { years }\end{array}$ \\
\hline George & $\begin{array}{l}\text { - } 28 \text { years old } \\
\text { - Current college student who works full time in } \\
\text { hospitality } \\
\text { - Has lived in the city } 2 \text { years }\end{array}$ \\
\hline Jawan & - 24 years old (no other information provided) \\
\hline Terry & - 22 years old from Dover, DE \\
\hline Larry & $\begin{array}{l}\text { - From Atlanta, GA (age not provided) } \\
\text { - Has lived in the city } 3 \text { months }\end{array}$ \\
\hline
\end{tabular}

$\mathrm{N}=8$. Data collected spring 2016. Pseudonyms are used. Locale is a city in Tennessee. 


\section{Findings}

The study examines some of the challenges, strengths, and decisions of a cadre of BMSM as they endeavor to navigate society. Three broad themes emerged: We Basically Claw Our Way to the Top: Overcoming Obstacles; We Don't Help Each Other: Invoking the Black Self-Help Tradition; and More Than HIV: Coping Mechanisms and Community-Building. Informed by a black feminist lens, the next section includes an analysis of each theme and corresponding representative quotes.

\subsection{We Basically Claw Our Way to the Top: Overcoming Obstacles}

The first emergent theme focuses on some of the daily challenges BMSM here face. Respondents are very candid about an array of problems, both individual and systemic. Taken together, their views illustrate both discernment and apprehensions about how race, gender, sexual orientation, age, and, in many instances, socioeconomics, intersect to influence their lives. For example, twenty-eight-year-old college student, George, attributes many of the challenges BMSM face to systemic forces;

Oppression, segregation, discrimination...Well, you know that Black Lives Matter protest...you know it's seen automatically as a violent threat. Even though it's a peaceful protest, it was squashed down by police force. You know, discrimination and segregation kind of go hand and hand you can see it in [name of city] in schools, in subdivisions...the segregation in [name of city].

In addition to mentioning chronic structural problems that have negatively affected blacks (Badgett, 2001; Choi et al., 2011; Dovidio \& Gaertner, 2004; Feagin, 2008), George and other respondents note more contemporary challenges that precipitated the Black Lives Matter (BLM) movement ${ }^{1}$ that was spearheaded by three members of his generation who self-identify as queer (Cobb, 2016; Sidner \& Simon, 2015; Wahlquist, 2017). BMSM here suggest that BLM has empowered them personally and collectively. Moreover, George's comment illustrates past problems that affect him as a black male in addition to the stigma and inequities he experiences as a BMSM. His racial identity appears to make him more keenly aware of problems sexual minorities face. Indicative of the oppression-resistance dichotomy from black feminism, George describes oppressive conditions with which he suggests BMSM often contend followed immediately by a mechanism, BLM, used to collectively resist these same problems (Collins, 1990, 2004). His remark is also a reminder of the political activist dimension for which black feminism is known (Crenshaw, 1994, 2017) and commonalities between black women and BMSM such that "issues of race, class, and gender inequality that effect black women's lives in America point to problems embedded in the fabric of the nation" (Harris-Perry, 2013: 16).

Similarly, Peter, a 25-year-old Masters student, recognizes the negative impact poverty has had in his life and in the lives of many of his peers;

It's disproportionate... as far as it comes too economically with us. We tend to live similar backgrounds, normally a single parent household, particularly mother based...we don't have a lot of the core foundations that our 
counterparts receive, and we basically claw our way to the top the best way we know how based off what we've learned or what we were ingrained with as we were born.

Peter references the disproportionate percentage of black youth who live in poverty as well as the feminization and juvenilization of poverty in the black community (Badgett, 2001; Barnes, 2005; Fellmeth, 2005). His thoughts also allude to attenuated experiences he believes BMSM experience at a young age that can have long-term consequences (Caughy \& O'Campo, 2006). Additionally, Peter provides an example of financial and non-financial problems associated with the intersection of race, class, gender, and, later, sexual orientation, and the matrix of domination that resulted in certain missed familial benefits associated with two-parent households (Collins, 1986, 1990, 2004; Crenshaw, 1994, 2017; Harris-Perry, 2004, 2013). These experiences have forced him to realize that only the most determined BMSM are able to garner the requisite human capital to make it in society (Balaji et al., 2012).

Twenty-five 25-year-old Samuel also describes how macro-level economic constraints can undermine aspirations, "Definitely, I would say financial support. Sometimes you might actually know what you want and what you want to accomplish, you just don't have the funds." Twenty-four-year-old Jawan extends this list of needs and suggests that BMSM could benefit from both emotional and financial support when they live away from their biological families;

My peers that I grew up with and work with - they go through trouble with housing. And even being able to get into different shelters. And I feel like that there should be more things implemented dealing with MSM... Whether black or white...it's hard to even find or even figure out those type of issues - I need more emotional support...Support and housing situations.

According to Samuel and Jawan, some MSM experience dire economic and emotional hardship (Arnold et al., 2014; Badgett, 2001; Battle \& Barnes, 2010; Battle et al., 2002; Blashill et al., 2011; Jones et al., 2010). For him, services to proactively educate and empower BMSM around sexuality would help combat shame and navigate societal challenges such as stigma. Moreover, access to welcoming transition houses and safe homeless shelters would help combat family abandonment and other hard times as well as provide a crucial stopgap when BMSM relocate to new areas (Battle et al., 2002). Although the lack of low-cost housing is a problem in society in general (Barnes, 2005), it appears to acutely affect BMSM whose challenges are often exacerbated based on the nexus of their social identities (Blashill et al., 2011; Choi et al., 2011; Collins, 1990; Graham et al., 2009; Jones et al., 2010). Although his own peer group has helped, additional active allies are needed. Jawan continues;

I know a couple of peers that have issues with being Trans and not being received in certain situations. Because you're always going up and down, even legal support...You don't really even focus on those types of things because you're always in flux, you're always focusing on 'What am I going to do? Where I am going?' So, you never have the time to even think about those 
things for yourself.

Jawan's comments above suggest common challenges experienced by members of the LGBTQIA community that transcend race and sexual orientation - and that result in instability, broadly defined. Informed by black feminism, Crenshaw's (1994) comment below parallels those of many BMSM here;

Intersectionality shapes the experiences of many women of color. Economic considerations - access to employment, housing, and wealth - confirm that class structures play an important part in defining the experience of women of color... But it would be a mistake to conclude from these observations that it is simply the fact of poverty that is at issue here. Rather, their experiences reveal how diverse structures intersect, since even the class dimension is not independent from race and gender (p. 2).

Like Crenshaw, respondents here posit that their problems should not be reduced solely to economic constraints, but reflect a plethora of interrelated structural forces they face - despite their social identity as males. Moreover, an onslaught of obstacles often means certain BMSM have difficulty fully understanding, prioritizing, and addressing problems. In such instances, short-term economic and non-economic support would literally buy them time to sort out their situations and determine solutions.

The theme in this section is a reminder of the effects of race- and class-based challenges, many stemming from childhood poverty, that continue to impact many BMSM and prevent them from gaining the requisite footing to meet basic daily needs or pursue their life goals. They describe systemic issues such as discrimination and oppression, economic deprivation, and lack of access to housing and quality education that ultimately constrain social mobility. For them, such problems can cause society to view them pejoratively. This theme also provides a reminder of how such inequities continue to affect blacks, regardless of gender and sexual orientation, such that, group mobilization, like BLM, results (Cobb, 2016; Collins, 2004; Sidner \& Simon, 2015; Wahlquist, 2017; West, 1993). Crenshaw (1994) provides a fitting thematic summary, "race can also be a coalition of straight and gay people of color, and thus serve as a basis for critique of...institutions that reproduce heterosexism" (p. 15).

\subsection{We Don't Help Each Other: Invoking the Black Self-Help Tradition}

Self-reflection, context-based wisdom (i.e., subjugated knowledges), and group empowerment are important concepts in the black feminist tradition (Choo \& Ferree, 2010; Collins, 1990, 2004; Harris-Perry, 2004, 2013; hooks, 1999, 2015). Just as BMSM in this study are cognizant of the negative effects of certain systemic forces on their lives, they are also candid about intra-group challenges. This second theme focuses on issues of agency, resilience, personal accountability, and collective intra-group mobilization certain respondents believe are crucial to survive and thrive - and that can be informed by black feminism. For example, according to 23-year-old student, Kenneth;

We don't help each other. Instead of us helping each other and bringing each other up...we're always knocking each other for one success, or what 
someone may have more or may have less... we don't work together, you know we, we're our own war itself.

Rather than blame structural forces for much of the challenges BMSM face, Kenneth's candid comment above suggests the need to look inward toward intra-group conflict. His remark suggests that dynamics such as self-interest, jealousy, envy, and miscommunication are preventing some BMSM from establishing relationships and networks to experience personal success, combat negative social forces, and build group solidarity (Balaji et al., 2012). And this lack of solidarity makes them more susceptible to the negative effects of homophobia, stigma, racism, and classism (Battle \& Barnes, 2010; Collins, 2004; Crenshaw, 2017; Dovidio \& Gaertner, 2004; Feagin, 2008). Dominique broadens the same critique;

Peer support...I've noticed when growing up in school. And just in society, we're all competitive, but we never stop to realize.... We all have tunnel vision. We never stopped to realize that maybe we need to help someone else in the struggle with us, maybe that they can help us out as well (23 years old student).

According to Dominique, the lack of mobilization among BMSM is indicative of malaise, unkindness, and lack of community in society in general (Feagin, 2008). Yet the impact of such disconnection tends to be more detrimental to economically and socially vulnerable groups such as BMSM who may lack certain economic resources and disproportionately experience stigma and discrimination (Badgett, 2001; Bogart et al., 2010; Choi et al., 2011; Graham et al., 2009). Crenshaw (1994) also suggests the importance of intra-group mobilization, "organized identity groups in which we find ourselves are in fact coalitions, or at least potential coalitions waiting to be formed" (p. 14).

Yet Peter, a 25-year-old graduate student, describes challenges BMSM might face to accomplish the goal of alliance-building, group empowerment, and support;

A lot of people don't even want to meet new friends...how can anyone make new friends if you're saying, 'No new friends?' How can you grow if you're only used to hanging out with your same friends?

In addition to tangible resources, Peter contends that BMSM could receive crucial emotional, psychological, and practical support by expanding their social networks. However, suspicions about "outsiders" and concerns about existing friendship boundaries undermine possible new ties (Jones et al., 2010; Means \& Jaegar, 2015; Oster et al., 2013). Such isolating views stand in stark contrast to the subjugated knowledges and subsequent solidarity that could result when minorities harness the benefits of being "outsiders within" (Collins, 1990). George agrees and provides areas in need of redress;

I kind of have two things and one is lack of positive role models. Because in the music industry, TV and all that, [for] a lot of the rappers and stuff, it's crime, drugs, sex, violence, and it kind of leaves our youth to go in that direction...It's like settling for that lifestyle, pursuing something different instead of getting an education, going against the grain. And then the other 
thing is medically. [BMSM are] afflicted by diseases disproportionally, diabetes, cancers, HIV, these affect our population more than they do others.

For the above graduate student, BMSM need expressive and instrumental support in the form of strategies for success and guidance to pursue paths more likely to result in upward mobility. Also needed are more role models who reflect the unique experiences, history, and challenges of BMSM. Similarly, black feminism describes the beneficence of interacting with persons who have experienced stigma and discrimination, but who somehow navigate these landmines while maintaining a healthy self-definition (Arnold et al., 2014; Choo \& Ferree, 2010; Collins, 1990, 2004; Harris-Perry, 2004, 2013; hooks, 1999, 2015; Means \& Jaeger, 2015; Peterson \& Jones, 2009). However, George's call for health-related solutions also suggests the some BMSM are thwarted from pursuing their aspirations because the intersection of risks found in their personal networks disproportionately exposes them to potentially debilitating and/or life threatening diseases (Collins, 1986, 2004; Millet et al., 2006; Millet et al., 2007).

This second theme illustrates that some BMSM here are willing to engage in self-reflection as they candidly discuss how to best navigate an often unwelcoming society (Choo \& Ferree, 2010; Collins, 1990, 2004; Harris-Perry, 2004, 2013; hooks, 1999, 2015). Some respondents describe pressure battling stereotypes and stigma associated with being black men; for most, these pressures are exacerbated due to their sexual orientation, age, and class position. They also recognize intra-group dynamics they consider emotionally and psychologically detrimental. Although insular networks appear to enable them to cope against negative stereotypes and stigma, they can also result in social isolation and resulting stressors (Arnold et al., 2014; Means \& Jaeger, 2015; Peterson \& Jones, 2009). Yet respondents also recognize the benefits of community- and resource-building coalitions among BMSM. Their sentiments harken back to both a self-help tradition common in the black community when facing personal and collective problems (Barnes, 2005; Billingsley, 1990) and black feminist edicts that encourage group activism (Choo \& Ferree, 2010; Collins, 1990; Harris-Perry, 2004, 2013; hooks, 1999, 2015). As Crenshaw (1994) posits, "intersectionality provides a basis for re-conceptualizing race as a coalition between men and women" (p. 16).

It is also noteworthy that BMSM describe certain situations that could be experienced by non-BMSM and illustrate both commonalities they have with these peers as well as compounded challenges unique to them due to the intersection of race, class, age, and sexual orientation (Arnold et al., 2014; Balaji et al., 2012; Battle \& Barnes, 2010). Yet according to black feminism, minorities such as BMSM must engage in everyday resistance and collective political activism for institutional change because, "if power as domination is organized and operates via intersecting oppressions, then resistance must show comparable complexity" (Collins, 2000: 218). Fostered by subjugated knowledges, intra-group mobilization can result in crucial push back against the matrix of domination that makes stigma, stereotypes, and other negative outcomes seem normative.

\subsection{More than HIV: Coping Mechanisms and Community-Building}

According to black feminism, safe spaces are crucial where marginalized groups can: 
rejuvenate; engage in self-care, self-reflection, and group support; develop counter-narratives; and, interpret their lives and experiences in ways they consider authentic. Collins (1990) notes, "this space is not only safe - it forms a prime location for resisting Objectification as the Other" (p. 95). Harris-Perry (2004) also describes the activist benefits of such spaces beyond their practical import; "ordinary spaces of everyday talk among African Americans serve as forums for dialogues...can be understood as expressions of black political ideology" (p. 3).

This third theme suggests that biological and fictive kin can help provide both safe spaces as well as other forms of social and economic support (Billingsley, 1990). BMSM describe varied family forms and networks, some beneficial and others problematic, on which they rely. Although BMSM acknowledge the importance of traditional families, they often describe a broader fictive network that helps sustain them;

Personally for me, it's my friends. That's just the culture that I've grown accustomed to. I'm around them a good majority of my personal time, so being around someone that frequently, you just create a special bond. So when I'm going through something and vice versa we kind of just help each other out.

Like women's groups historically known to build solidarity and support, some BMSM have similar alliances (Collins, 1990, 2004). For example, Peter has developed close bounds with a group of peers based on their lived experiences and because such persons have behaved like family by providing him with unconditional love and support. For him, the genuine, consistent instrumental help in friendship networks constitutes family beyond blood ties (Balaji et al., 2012; Billingsley, 1990; Oster et al., 2013). Yet this same respondent provides a less constructive way he believes some of his peers find support;

It's not my best practice, but I just want to be one-hundred percent honest and I think it's something that needs to be included, a lot of people turn to substances for support... alcohol, marijuana, those things are so recreationally used now. It just makes it a lot easier, to turn to those things for social support...for the turn up. That makes it a lot easier for that to be your comfort.

Although he is reticent to include this less positive alternative to the discussion, Peter seems compelled to acknowledge that some BMSM may use substances as a source of solace (Blashill et al., 2011). He suggests that these options are both easily accessible, always "welcoming," and available for interested imbibers.

Just as support can take the form of positive people in one's life or substance use, college student Dominque comments on other unhealthy behavior he believes can become a substitute for genuine relationships, friendships, and safe spaces;

Invitations of different things, it could be an invitation to a sex party. It could be an invitation to a blowout or to a smoke out. It can be a house party. And you basically you decide what you want to go based off of how that person looks or if there's any attraction to that person. Or if you just want to have a 
good time that night, so you just get a random message from someone you don't know.

Kenneth echoes this comment, "a significant other...either for temporary or the moment." And Peter, completes the illustration; "I want to add on to that...I just wanted to say that could be temporary or long term (emphasis is his). I'm saying a nice way of a hookup or something like that...there we go, hook up." Dominque, Kenneth, and Peter describe social gatherings, both sexual and non-sexual, were some BMSM may go to feel connected. Although the first respondent provides details about the nature and scope of these gatherings, Kenneth alludes to the search for companionship.

Respondents discuss a "hidden world" that includes numerous venues for gathering and connecting socially and/or sexually such as: house parties for social interactions; smoke-out/blow-out parties or spaces where people met to smoke marijuana; sex parties; and, health clubs. Social media mobile applications like Grindr, Jack'd, SCRUFF, and OkCupid allow BMSM to communicate peer to peer; this communication can be a source of emotional support, information sharing, social ties, or finding sexual/romantic partners (Martinez et al., 2014). Yet upon reflection, all three BMSM describe the temporary nature of many of these real and/or virtual spaces and suggest that they are often ineffective in helping BMSM experience the platonic and romantic ties they really seek.

Black feminism provides a description and prescriptive for their sentiments that have even broader implications; "when individual African American women and men strive to develop honest bodies and to reclaim the erotic as a site of freedom, and love as a source of affirmation for self and others, they challenge the spread of HIV/AIDS" (Collins, 1990: 290). Her statement points to the importance of self-love, self-definition, self-reflection, and other positive strategies known to lead to beneficial outcomes for marginalized groups. Yet the above remarks by BMSM also illustrate the diverse choices and experiences that exist in their community as well as the reality that, like black women, not all BMSM choose to embrace tenets associated with black feminism (Choo \& Ferree, 2010; Collins, 1990; Harris-Perry, 2004, 2013; hooks, 1999).

Several respondents describe other beneficial, long-term social ties with other BMSM. These relationships represent fictive kin that creatively extend a traditional definition of family (Billingsley, 1992; Oster et al., 2013). According to Dominique, although they were not biologically related, each member of his fictive family embraced certain roles and responsibilities - father, mother, child, and siblings - and was accountable to the collective. This non-traditional family met economic and non-economic needs, both emotional and practical. He continues by detailing the benefits and challenges found in any "typical" family as well as possible self-less expressions;

It goes beyond living to get. Like I can help you with a job, like anything, whatever you need..., it goes, it goes, it goes, as far as how much you let it go like...they love you or can go as quick - as first they love you then they hate you. It just depends. Normal family basically. Just without all the ties. 
Domonique's remark above illustrates the strengths and frailties of this family form - like other "normal" families. His experience is also important because it belies stereotypes that suggest sexual encounters are requisite for long-term commitments among BMSM as well as how familial ties can emerge based on necessity and ingenuity. Furthermore, in order to be adaptive and resilient, subjugated knowledges suggest the need for innovative social identities and group-determined definitions of what constitutes a family (Collins, 1990, 2004).

Below, Peter provides a broad illustration of how some social connections can emerge among BMSM;

I just want to kind of sum up all of this that we heard about parties. I guess they cater to the person that's throwing them individually. So if I'm throwing the sex party, it's because that's my status quo - that's what I like. Me, per se, I throw socials at my house, but my social is more - get together and sing karaoke. Play cards. So, I think it just really depends specifically who that individual is. And they look for like-minded people.

According to Peter, like non-BMSM, the type of social connections BMSM initiate and engage in depend on their interests, personalities, and desires. While acknowledging that some of his peers seem more interested in sexual connections, Peter describes other interests that are not sex-based. His remark also challenges existing stereotypes about the lives and needs of BMSM and presents a counter-narrative about their social needs.

Jawan's comment below summarizes the message among the BMSM in this study as they search for individual and collective ways to combat problems for empowerment;

Don't censor like every event... well not necessarily censor, but censor is not the word I'm looking for.... around HIV... Don't make HIV the focus...You can make it a sub-focus, but not necessarily the only focus...don't make HIV the sole focus of the BMSM community.

Jawan's observation reflects a common concern - and challenge - among respondents in this study. Although they recognize the specter of HIV/AIDS in the BMSM community, they refuse to be reduced to a statistic, health prediction, or to their sexual identities (Millett et al., 2007). This means that Jawan rejects controlling images (i.e., societal definitions) that reduce BMSM to sexual behavior or HIV-related stereotypes (Collins, 1990). Moreover, respondents do not consider HIV the eventual outcome for their lives (Battle \& Barnes, 2010).

Jawan and other BMSM here espouse a broader self-definition associated with more positive identity politics that parallels Crenshaw's (1994) following edict; "This process of recognizing as social and systemic what was formerly perceived as isolated and individual has also characterized the identity politics of people of color and gays and lesbians, among others. For all these groups, identity-based politics has been a source of strength, community, and intellectual development" (p. 1). Just as families, fictive and biological, as well as friendship networks can be complicated collectives, Jawan acknowledges that, like other BMSM, he is nuanced in his beliefs, behavior, needs, and goals. For him and other BMSM, 
reductionist views, stereotypes, and stigma in society only undermine the ability to effectively acknowledge, understand, and thoughtfully respond to the varied needs of BMSM.

\section{Discussion and Conclusion}

BMSM in this study describe a unique set of experiences and challenges they face as a result of race, class, age, and sexual behavior as well as the intersection of the same identities. Some situations are not new (i.e., economic problems and discrimination), others are more contemporary (i.e., social media-driven interactions), and still others are re-occurring, but finally getting attention in the media and academic circles. Respondents appear to be very social, have relatively strong networks (but need more), technologically savvy, and endeavor to maximize the resources available to them. Although they experience stigma and other inequities, BMSM here also acknowledge social support from certain family members, fictive kin, and friendship networks. These human resources provide both instrumental and expressive benefits. In contrast, they recognize that other alternative networks and activities may provide temporary social and intimate connections, but are associated with risky behavior and negative outcomes (Millet et al., 2006; Millet et al., 2007).

This study does not do justice to the nuanced lives of the BMSM who shared their stories. Nor does it capture all the strengths of a black feminist lens. However, several noteworthy results provide a glimpse into both these domains. A key finding here is the importance of their fictive BMSM families which include men that intentionally and proactively form social networks for emotional support, housing, employment information, and in response to common problems. They act as a surrogate family for BMSM who may be isolated from their biological families for varied reasons (Billingsley, 1992; Oster et al., 2013). It appears that social media may facilitate these arrangements. However, these arranged families can have positive or negative influences depending on the motives of family members. Another notable result that emerged here shows that certain BMSM experience tensions between expected entitlements associated with maleness and their more marginalized identity based on sexual behavior where the former social identity is minimized as a result of the intersection of race, class, sexual orientation, and age. Additional studies based on in-depth interviews are needed to consider whether and how BMSM understand and rank their social identities based on intra- and inter-group factors and the related implications.

Another important result suggests the applicability of black feminism as a robust theory to examine the experiences of BMSM. As suggested by this paradigm, BMSM expressed insights or subjugated knowledges about their experiences, personal choices, and systemic correlates to the challenges they and other BMSM often face. Part of this process meant identifying, yet rejecting controlling images, and thinking about themselves in favorable ways. They were also keenly aware of the importance of networks, social support, safe spaces, and broader forms of activism to empower blacks, in general, and BMSM, in particular. For respondents, everyday forms of resistance must involve self-reflection as well as inter- and intra-group candor and critique. Equally important, these results illustrate diversity even 
among this limited sample in terms of attitudes and behavior that suggests the importance of diverse strategies, initiatives, and programs to meet the needs of this population.

Although thoughtful and insightful, the thick descriptions and prescriptives from this small group cannot be generalized to the broader BMSM population. Existing studies parallel some of my findings, including: exposure to discrimination, stigma, racism, and homophobia (Arnold et al., 2014; Bennett, 2013; Feagin, 2008); benefits of family, friendship networks, and community support groups (Balaji et al., 2012; Billingsley, 1990; Oster et al., 2013); economic challenge (Badgett, 2001); emotional and psychological challenges as well as strengths linked to their intersectional identities (Blashill et al., 2011; Collins, 1986; Graham et al., 2009; James et al., 2010); coping strategies (Choi et al., 2011; Cobb, 2016); and, collective mobilization in the black community (Sidner \& Simon, 2015; Wahlquist, 2017). However, additional studies are needed based on larger samples, using multi-disciplinary lenses like black feminism, and from varied regions of the country to corroborate and/or extend these findings. Moreover, further research should assess how black feminism is differentially experienced among BMSM who, despite their marginalized position, are also part of an entitled gender group.

Most respondents here have supportive families and friends; they acknowledge that other BMSM are not as fortunate. Overwhelmingly, they suggest the need for safe spaces or places and people where they can be authentic, communicate openly, and experience emotional support and encouragement (Harris-Perry, 2004). In addition to empathetic mentors for support, BMSM describe the need for more practical support in the form of: increased access to legal assistance, substance abuse treatment and education; access to health insurance and health care; and, low-cost housing. Meeting these needs may not eliminate all the challenges or stigma they experience, but such change would enable BMSM to become more economically and non-economically stable - and consequently better equipped and empowered to navigate society and push back against ill treatment. Although BMSM here seem to be relatively adaptive and resilient, they recognize that they will have difficulty maximizing their potential without the support and thoughtful assistance of a more welcoming, inclusive society.

\section{Acknowledgement}

The research is financed by a grant from HIV CBI - Department of Health and Human Services: Substance Abuse and Mental Health Services Administration, Center for Substance Abuse Prevention (project title - CBI: SA and HIV Prevention Services for African American Young MSM).

\section{References}

Arnold, E., Rebchook G., \& Kegeles, S. (2014). Triply cursed: Racism, homophobia and HIV-related stigma are barriers to regular HIV testing, treatment adherence and disclosure among young black gay men. Culture, Health \& Sexuality, 16(6), 710-22. 
https://doi.org/10.1080/13691058.2014.905706

Badgett, M. V. (2001). Money, myths, and change: The economic lives of lesbians and gay men. Chicago: University of Chicago Press.

Balaji, A. et al. (2012). Role flexing: How community, religion, and family shape the experiences of young black men who have sex with men. AIDS Patient Care and STDs, 26(12), 730-37. https://doi.org/10.1089/apc.2012.0177

Barnes, S. (2013). To welcome or affirm: black clergy views about homosexuality, inclusivity, and church leadership. Journal of Homosexuality 60, 1409-33. https://doi.org/10.1080/00918369.2013.819204

Barnes, S. (2009). The influence of black church culture: How black church leaders frame the HIV/AIDS discourse. Journal of Inter-Religious Dialogue, 2, 1-17.

Barnes, S. (2005). The cost of being poor: A comparative study of life in poor urban neighborhoods in Gary, Indiana. New York: State University Press of New York.

Battle, J., \& Barnes, S. (2010). Black sexualities: Probing power, passions, practices, and policies. New Brunswick, NJ: Rutgers University Press.

Battle, J., Cohen, C., Warren, D., Fergerson, G., \& Audam, S. (2002). Say it loud I'm black and I'm proud: Black pride survey 2000. New York: The Policy Institute of the National Gay and Lesbian Task Force. Retrieved from http://www.thetaskforce.org/static_html/downloads/reports/reports/SayItLoudBlackAnd Proud.pdf

Baumrind, D. (1995). Commentary on sexual orientation: Research and social policy implications. Developmental Psychology, $\quad 31(1), \quad$ 130-36. https://doi.org/10.1037/0012-1649.31.1.130

Bennett, C. (2013). Stigma increases HIV infections among young black gay men. Edge Media Network. Retrieved from http://www.edgemedianetwork.com/

Berry, M., Raymond, H., \& Mcfarland, W. (2007). Same race and older partner selection may explain higher HIV prevalence among black men who have sex with men. Aids, 21(17), 2349-50. https://doi.org/10.1097/QAD.0b013e3282f12f41

Berrill, K. (1990). Anti-gay violence and victimization in the United States. Journal of Interpersonal Violence, 5(3), 274-94. https://doi.org/10.1177/088626090005003003

Billingsley, A. (1992). Climbing Jacob's ladder: The enduring legacy of African-American families. New York: A Touchstone Book.

Blashill, A., Perry, P., \& Safren, S. (2011). Mental health: A focus on stress, coping, and mental illness as it relates to treatment retention, adherence, and other health outcomes. Current HIV/AIDS Reports, 8(4), 215-22. https://doi.org/10.1007/s11904-011-0089-1

Bogart, L., Wagner, G., Galvan, F., \& Klein, D. (2010). Longitudinal relationships between 
antiretroviral treatment adherence and discrimination due to HIV-serostatus, race, and sexual orientation among African-American men with HIV. Annals of Behavioral Medicine, 40(2), 184-90. https://doi.org/10.1007/s12160-010-9200-x

Caughy, M., \& Campo, P. (2006). Neighborhood Poverty, Social Capital, and the cognitive development of African American preschoolers. American Journal of Community Psychology, 37(1-2), 141-54. https://doi.org/10.1007/s10464-005-9001-8

Center of Disease Control and Prevention. (2015). HIV among African Americans CDC fact sheet. Retrieved from http://www.cdc.gov/nchhstp/newsroom/docs/cdc-hiv-aa-508.pdf.

CDC. (2016). HIV Among gay and bisexual men. Retrieved from https://www.cdc.gov/hiv/group/msm/index.html.

CDC. (2016a). HIV among African American gay and bisexual men. Retrieved from https://www.cdc.gov/hiv/group/msm/bmsm.html.

Choi, K., Han, C., Paul, J., \& Ayala, K. (2011). Strategies for managing racism and homophobia among U.S. ethnic and racial minority men who have sex with men. AIDS Education and Prevention, 23(2), 145-58. https://doi.org/10.1521/aeap.2011.23.2.145

Choo, H. Y., \& Ferree, M. (2010). Practicing intersectionality in sociological research: A critical analysis of inclusions, interactions, and institutions in the study of inequalities. Sociological Theory, 28(2), 129-149. https://doi.org/10.1111/j.1467-9558.2010.01370.x

Cobb, J. (2016). The matter of black lives: A new kind of movement found its moment. what will its future be? The New Yorker, (March 14). Retrieved from http://www.newyorker.com/magazine/2016/03/14/where-is-black-lives-matter-headed.

Collins, P. (2004). Black sexual politics: African Americans, gender, and the new racism. New York: Routledge.

(1990). Black feminist thought: Knowledge, consciousness, and the politics of empowerment. New York, NY: Routledge Classics.

(1986). Learning from the outsider within: The sociological significance of black feminist thought. Social Problems, 33(6), S14-S32.

Cook, F. L. (1979). Who should be helped? Public support for social services. Beverly Hills, CA: Sage Publishers.

Crenshaw, K. (2017). Kimberlé Crenshaw on intersectionality, more than two decades later. Retrieved from https://www.law.columbia.edu/pt-br/news/2017/06/kimberle-crenshaw-intersectionality

(1994). Mapping the margins: Intersectionality, identity politics, and violence against women of color. In M. Fineman \& R. Mykitiuk (Eds.), The public nature of private violence (pp. 93-118). New York: Routledge Press.

Dovidio, J., \& Gaertner, S. (2004). Aversive racism. In Olson, J., \& M. P. Zanna (Eds.), 
Advances in experimental social psychology (pp. 1-52). San Diego, CA: Academic Press.

Feagin, J. (2008). The continuing significance of race: Anti-black discrimination in public places. In D. Grusky (Ed.), Social stratification: Class, race, and gender in sociological perspective (pp. 703-708). Boulder, CO: Westview Press.

Fellmeth, R. (2005). Child poverty in the United States. Human Rights: Journal of the Section of Individual Rights \& Responsibilities, 32(1), 2-19.

Graham, L., et al. (2009). Exploring the mental health of black men who have sex with men. $\begin{array}{llll}\text { Community Mental Health } & \text { 272-84. }\end{array}$ https://doi.org/10.1007/s10597-009-9186-7

Hall, H. (2008). Estimation of HIV incidence in the United States. Jama, 300(5), 520-34. https://doi.org/10.1001/jama.300.5.520

Harris-Perry, M. (2013). Sister citizen: Shame, stereotypes, and black women in America. New Haven, Connecticut: Yale University Press. . (2004). Barbershops, bibles, and BET: Everyday talk and black political thought. Princeton, NJ: Princeton University Press.

Hawkins, B. D. (2011). 30 years later: AIDS experts reflect on efforts to eradicate the disease, create awareness about how it is transmitted. Diverse, (Sept. 11), 16-18.

Hooks, B. (2015). Ain't I a woman: Black women and feminism (2nd ed.). New York: Routledge Press. (1999). Talking back: Thinking feminist, thinking black. New York: South End Press.

Hsieh, H., \& Shannon, S. (2005). Three approaches to qualitative content analysis. $\begin{array}{llll}\text { Qualitative } \quad \text { Health } & \text { Research, } & \text { 15(9), } & \end{array}$ https://doi.org/10.1177/1049732305276687

Jenkins, M., Lambert, E., \& Baker, D. (2007). The attitudes of black and white college students toward gays and lesbians. Journal of Black Studies, 39(4), 589-613. https://doi.org/10.1177/0021934707299638

Jones, K., Wilton, L., Millett, G., \& Johnson, W. (2010). Formulating the stress and severity model of minority social stress for black men who have sex with men. African Americans and HIV/AIDS, 223-38. https://doi.org/10.1007/978-0-387-78321-5_12

Krippendorf, K. (1980). Content analysis: An introduction to its methodology. Beverly Hills, CA: Sage Publications.

Lemelle, A., \& Battle, J. (2004). Black masculinity matters in attitudes toward gay rights. Journal of Homosexuality, 47, 39-41. https://doi.org/10.1300/J082v47n01_03

Martinez, O. et al. (2014). Still a hard-to-reach population? Using social media to recruit Latino gay couples for an HIV intervention adaptation study. Journal of Medical 
Internet Research, 16(4). http://dx.doi: 10.2196/jmir.3311

Means, D., \& Jaeger, A. (2015). Spiritual borderlands: A black gay male college student's spiritual journey. Journal of Student Affairs Research and Practice, 52(1), 11-23. https://doi.org/10.1080/19496591.2015.1009341

Millett, G., Peterson, J., Wolitski, R., \& Stall, R. (2006). Greater risk for HIV infection of black men who have sex with men: A critical literature review. American Journal of Public Health, 96(6), 1007-19. https://doi.org/10.2105/AJPH.2005.066720

Millett, G., Flores, S., Peterson, J., \& Bakeman, R. (2007). Explaining disparities in HIV infection among black and white men who have sex with men: A meta-analysis of HIV risk behaviors. Aids, 21(15), 2083-91. https://doi.org/10.1097/QAD.0b013e3282e9a64b

Nelson, E., \& Krieger, S. (1997). Changes in attitudes toward homosexuality in college students. Journal of Homosexuality, 33(2), 63-81. https://doi.org/10.1300/J082v33n02_04

Neuendorf, K. A. (2002). The content analysis guidebook. Thousand Oaks, CA: Sage.

Oster, A. et al. (2013). Network analysis among HIV-infected young black men who have sex with men demonstrates high connectedness around few venues. Sexually Transmitted Diseases, 40(3), 206-12. https://doi.org/10.1097/OLQ.0b013e3182840373

Peterson, J., \& Jones, K. (2009). HIV prevention for black men who have sex with men in the United States. American Journal of Public Health, 99(6), 976-80. https://doi.org/10.2105/AJPH.2008.143214

Reisner, S. et al. (2009). Clinically significant depressive symptoms as risk factor for HIV infection among black MSM in Massachusetts. AIDS Behavior, 13(4), 798-810. https://doi.org/10.1007/s10461-009-9571-9

Sidner, S., \& Simon, M. (2015). The rise of black lives matter: Trying to break the cycle of violence and silence. CNN, (Dec. 28, 2015). Retrieved from http://www.cnn.com/2015/12/28/us/black-lives-matter-evolution/index.html.

Stewart, D., \& Shamdasani, P. (1990). Focus groups: Theory and practice. Newbury Park, CA: Sage Publications.

Strauss, A., \& Corbin, J. (1990). Basics of qualitative research: Grounded theory procedures and techniques. Newbury Park, CA: Sage.

Tennessee Dept. of Health. (2013). Education, involvement, testing urged to end HIV/AIDS crisis. Retrieved from https://news.tn.gov/node/10248

Tennessee Dept. of Health. (2013a). HIV disease in metro/county: HIV disease epi-profile for Davidson County 2013. Retrieved from http://health.state.tn.us/STD/data.shtml

Turner, M. (2012). Nashville CARES promotes black HIV/AIDS awareness day, Nashville Cares. Retrieved from http://www.nashvillecares.org/news/2012/02/08/ 


\section{Macrothink}

Journal of Sociological Research

ISSN 1948-5468 2020, Vol. 11, No. 1

Wahlquist, C. (2017). Black lives matter awarded 2017 Sydney Peace Prize. The Guardian (May 22 , 2017).

Retrieved

from

https://www.theguardian.com/us-news/2017/may/23/black-lives-matter-awarded-2017-s ydney-peace-prize

Weir, S. et al. (2003). From people to places: Focusing AIDS prevention efforts where it matters most. Aids, 17(6), 895-903. https://doi.org/10.1097/00002030-200304110-00015

West, C. (1993). Race Matters. Boston: Beacon Press.

Note

Note 1. The Black Lives Matter movement was founded in the United States by Patrisse Cullors, Alicia Garza and Opal Tometi after the 2013 acquittal of George Zimmerman, who was accused of murdering black teenager Trayvon Martin.

\section{Copyright Disclaimer}

Copyright for this article is retained by the author(s), with first publication rights granted to the journal.

This is an open-access article distributed under the terms and conditions of the Creative Commons Attribution license (http://creativecommons.org/licenses/by/3.0/). 